\title{
Kraftwerk e a ausência dos corpos \\ Notas sobre um show no Rio de Janeiro em 2004 (e outro em 2009)
}

\section{José Cláudio Siqueira Castanheira}

Mestrando em Comunicação Social pela Universidade do Estado do Rio de Janeiro (UERJ).

\section{RESUMO}

Este artigo procura pensar a virtualização dos corpos na cultura contemporânea através de três eixos principais. O primeiro seria o de como o som e a imagem são separados de sua materialidade através de novas técnicas de construção audiovisual. Usando um show da banda alemã Kraftwerk como exemplo, demonstro como a música eletrônica passou a se valer de um objeto sonoro desvinculado de um corpo empírico, o que pode ser estendido para a produção de imagens de síntese. Num segundo momento trato de como os corpos são virtualizados por essas tecnologias. Esse tipo de pensamento vai resultar em construções sócio-tecnológicas como os conceitos de Inteligência Artificial e de Ciborgues. Por fim tento mostrar como o mundo real, em suas diversas instâncias, desde a econômica até a cultural, tende a virtualizar-se, opondo a experiência descorporificada à materialidade.

Palavras-chave: corpo, virtualização, cibercultura, tecnologia.

\section{ABSTRACT}

This article looks for to think the virtualization of bodies in contemporary culture through three main axes. The first one would be how sound and image are separated of their materiality through new techniques of audiovisual construction. Using a show of the German band Kraftwerk as example, I demonstrate how electronic music began to use a sound object disentailed of an empirical body, what can be extended to the production of synthesis images. In a second moment I discuss how bodies are virtualized by these technologies. This type of thought results in socio-technological constructions such as the concepts of Artificial Intelligence and Cyborgs. Finally I try to show how the real world, in its diverse instances, from the economic to the cultural one, tends to virtualize itself, opposing the disembodied experience to materiality.

Keywords: body, virtualization, cyberculture, technology. 
Music can organize our bodies and keep our minds in order. (Paul Hegarty)

Harder, better, faster, stronger. (Daft Punk)

MEINE DAMEN UND HERREN, avisa a grande tela atrás do palco.

LADIES AND GENTLEMEN / HEUTE ABEND / DIE MENSCH MASCHINE / KRAFTWERK

Em uma voz robótica ecoam os versos da primeira música. The Man, Man-Machine. Semi-human being.

Os homens-máquina (ou máquinas humanas). A metáfora é direta. No palco, os quatro integrantes da banda Kraftwerk (estação de força) movem-se muito pouco, permanecendo atrás de suas bancadas. Operam instrumentos de forma discreta, quase imperceptivelmente. Concentrados, vestindo roupas sóbrias, não são muito diferentes de executivos que encontraríamos em qualquer escritório.

O ritmo é constante, repetitivo, hipnótico. As frases desenrolam-se padronizadas. A palavra, quando há, é mínima. Tem a força maior que seu significado lingüístico, é quase rito. É ritmo, é padrão, é catarse.

Alguns indícios do universo em que estamos entrando: não falamos de corpos, pelo menos em um sentido estritamente orgânico. Corpos aqui são híbridos, a começar pelos títulos das músicas. Sofrem intervenções de natureza tecnológica, seja no campo biomédico (em músicas como Elektro Kardiogram, Vitamin) (1), seja no campo propriamente eletrônico (Computer World, Home Computer, Pocket Calculator). O corpo mecanizou-se (The Robots). Os grandes avanços industriais tornaram-se modelos de interação, de mobilidade, de grandes distâncias vencidas com facilidade (Autobahn, Trans Europe Express). As redes tomaram o mundo.

Com roupas que transformam seus corpos em wireframes (2) de programas 3D, Ralf Hütter, Florian Schneider, Fritz Hilpertt e Henning Schmitz “atravessam o espelho de Alice”. Tornam-se sua própria imagem virtualizada, como mostra o videoclipe da década de 80, Musique Non Stop.

A proposta deste trabalho é a de pensar a virtualização do corpo como opção estética. Tanto no espetáculo da banda Kraftwerk, como em outras manifestações artísticas contemporâneas, o corpo aparece como um empecilho, algo que pode ser dispensado caso não possa ser aperfeiçoado. É o caso das performances do artista australiano Stelarc, onde seu próprio corpo é objeto de intervenções tecnológicas. Partindo do conceito de pós-humano apresentado por autores como Paula Sibilia, André Lemos e Katherine Hayles, pretendo mostrar também como a idéia de virtualização ultrapassa os limites do estético e se instala em outras esferas da sociedade atual. O social e o econômico passam por um processo de numerização, segundo autores como Jeremy Rifkin. O corpo humano acaba sendo afetado, em outros níveis, por mais esse processo de desmaterialização. 


\section{Synthetic electronic sounds. Industrial rhythms all around}

Estamos cercados por um universo tecnológico, sem dúvida. Tanto fisica quanto imageticamente. Seqüenciadores, teclados, drum-machines e outros afins são apêndices corriqueiros em apresentações de artistas de vários gêneros há muito tempo. Mas aqui, parece, o instrumento é mais que um meio, é uma extensão (McLUHAN, 2005). Compõe um conjunto com o corpo, mas também integra o imaginário. A máquina é ferramenta, mas também é o homem. Se pensarmos a música eletrônica em seus primórdios, veremos que ela se baseia no descolamento do som de uma abstração lingüística (a linguagem musical) que já não atendia às demandas criativas de artistas da musique concrète (3) e da elektronische musik (4). A música eletrônica buscava a síntese de novos sons, puros e submetidos a uma estruturação rígida, científica. A música concreta de Pierre Schaeffer, em um caminho diferente, retomando o conceito de redução fenomenológica de Husserl, procurava o caráter acusmático do som, uma escuta reduzida. O que fazia o som valer, significar por si próprio, além da abstração musical, eram suas características intrínsecas: como foi produzido, que materiais foram usados, de que modo (SCHAEFFER, 1966). Mas a preocupação com o uso do ruído de maneira musical não era nova nos anos 50. Décadas antes, Luigi Russolo, em seu manifesto, nos dizia:

A arte musical procurou e obteve primeiramente a pureza e a doçura do som, depois amalgamou diversos sons, preocupando-se em acariciar os ouvidos com suaves harmonias. Hoje, a arte musical, complicando-se cada vez mais, procura o amálgama de sons mais dissonantes, estranhos e estridentes para os ouvidos. Deste modo nós nos aproximamos do som-ruído. Essa evolução da música é paralela à multiplicação das máquinas, que colaboram em qualquer situação com o homem. Não apenas na atmosfera barulhenta das grandes cidades, mas também no campo, até ontem normalmente silencioso, a máquina criou hoje tanta variedade e concorrência de ruídos que o som puro, em sua escassez e monotonia, não suscita mais emoções (RUSSOLO, 1916: 10).

As máquinas movidas a vapor, as engrenagens, as máquinas musculares (SANTAELLA, 1997) da Revolução Industrial representaram para os futuristas uma nova relação da arte com o corpo.

Tanto de uma forma como de outra - na bricolagem da música concreta, assim como na geração eletrônica de ondas sonoras -, vemos que o som quer se descolar do corpo, procura seu sentido independentemente do ente gerador, do objeto empírico que, para artistas como Pierre Schaeffer, Satie e Varèse, não devia ser o mais importante na experiência auditiva.

A paisagem sonora mundial começa a povoar-se de novos elementos. O congestionamento sonoro afeta a maneira pela qual o ser humano relaciona-se com o mundo. A eletricidade abole distâncias e a velocidade passa a ser uma dimensão decisiva para a percepção. Os novos sons são transmitidos "esquizofonicamente através do tempo e do espaço para viverem existências amplificadas ou multiplicadas" (SCHAFER, 1997: 107). A condição frágil e inapta do corpo para determinadas atividades vai modelar uma nova forma de pensálo e a suas extensões. 


\section{я твои слуга. я твои работник (Eu sou о seu servo. Eu sou o seu trabalhador)}

As máquinas musculares, meras reprodutoras de movimentos rudimentares do homem, também o amplificam, o tornam mais eficiente. O tempo de execução de tarefas é radicalmente diminuído, as distâncias encurtam. Tudo trabalha para uma maior e melhor produção ou, como mostra Foucault, para uma disciplina social:

O tempo medido e pago deve ser também um tempo sem impureza nem defeito, um tempo de boa qualidade, e durante todo o seu transcurso o corpo deve ficar aplicado a seu exercício. A exatidão e a aplicação são, com a regularidade, as virtudes fundamentais do tempo disciplinar (FOUCAULT, 2007: 129).

A sociedade disciplinar, em seu processo de constituir esse corpo dócil, não pode pensar o homem como massa ou grupo. Esse poder tem que ser exercido individualmente. Para isso vale-se de procedimentos para organizar o espaço. Esse espaço (o da produção, o da educação, o espaço militar, o religioso) deve ser bem delimitado, cercado, separado dos espaços ordinários. Além disso, o indivíduo deve ser localizável nesse espaço. "Importa estabelecer as presenças e as ausências, saber onde e como encontrar os indivíduos" (FOUCAULT, 2007: 123). Esse quadriculamento e a necessidade de se criar um espaço útil vão determinar as novas funcionalidades do corpo humano.

Esse processo tem a exatidão como meta. Contudo, o corpo não é de todo exato. As máquinas tratam de conformá-lo, ordená-lo. Santaella chama de sensórias as máquinas que, amplificando os sentidos humanos, afinam sua percepção do mundo. Abrem as portas de um universo macro e microscópico, invisível até então (SANTAELLA, 1997).

O relógio, por exemplo, pode ser visto como máquina emblemática do capitalismo industrial:

Esse aparelhinho singelo e preciso, cuja única função consiste em marcar mecanicamente a passagem do tempo, simboliza como nenhum outro as transformações ocorridas na sociedade ocidental em sua árdua transição para o industrialismo e para a lógica disciplinar (SIBILIA, 2002: 24).

Podemos pensar ainda em ainda um terceiro tipo de máquina. Uma máquina que poderia ajudar a compreender, e talvez simular, a inteligência humana. A máquina cerebral. Enquanto as máquinas sensórias tornaram-se grandes produtores de signos, às máquinas cerebrais coube a função de processar essa enorme quantidade de signos produzida (SANTAELLA, 1997). 


\section{Perfection mékanik. Aéro dynamik}

Como extensões dos nossos sentidos, essas máquinas sensórias e, posteriormente, as máquinas cerebrais, modificam substancialmente a nossa relação com a realidade. Como se vê, o corpo acaba sendo a medida de toda inovação tecnológica. É o parâmetro fundamental para essa relação com o objeto tecnológico.

Para Merleau-Ponty, toda apreensão do mundo passa necessariamente pelo corpo.

Devemos agora generalizar, dizer que o que é verdade para a percepção é verdade também na ordem da intelecção e que de um modo geral toda a nossa experiência, todo o nosso saber comportam as mesmas estruturas fundamentais, a mesma síntese de transcrição, o mesmo gênero de horizontes que acreditamos encontrar na experiência perceptiva? (MERLEAU-PONTY, 1990: 54).

A pergunta de Merleau-Ponty pode ser encarada como uma afirmação. De fato, ao aproximar nossos sentidos de uma outra realidade, escondida por dimensões antes inacessíveis, essas máquinas sensórias criam um novo mundo e, conseqüentemente, um novo homem. Não há como dissociar o que vemos, ouvimos ou sentimos do que pensamos existir. Quando as máquinas excedem nossos sentidos elas nos excedem, por conseqüência. Esse excesso é assumido já como parte constituinte e natural de nossa construção humana.

Talvez venha daí uma preocupação excessiva de alguns autores sobre os limites dessa construção, quando as velocidades crescem ao ponto de não podermos usar nosso corpo mais como medida para explicar o mundo.

Como podemos ter deixado de acreditar em nossos próprios olhos para crer tão facilmente nos vetores da representação eletrônica e, sobretudo, no vetor-velocidade da luz? Não estaríamos nós diante de um obscurantismo da relatividade, de um culto solar reencontrado? (VIRILIO, 1993: 31).

Bom, mas aqui chegamos a um ponto confuso onde o mundo, que era compreendido através do nosso corpo, adquire uma velocidade tamanha que o corpo não pode mais medi-lo. Não seria o caso de pensar como esse corpo avança no sentido de sempre acompanhar o mundo, mesmo que esses avanços sejam exteriores ao próprio corpo? Não seria ele capaz de acompanhar qualquer aumento de velocidades, uma vez que esses aumentos sempre terão esse corpo, ainda que amplificado, como medida? As próteses tecnológicas não seriam também uma sua parte?

Pierre Lévy nos diz que as técnicas nos trazem sempre esquemas imaginários, implicações sociais e culturais. As tecnologias são processos sociais, culturais e materiais repetidos até tornarem-se mecanismos. Têm origem no trabalho executado por pessoas e não podem ser compreendidas separadamente dessas pessoas. A realidade virtual, ou seja, aquela vivenciada através de periféricos conectando o corpo humano ao computador, é construída a partir de sensações artificiais (podemos perguntar: seriam mesmo artificiais?) simulando a visão, o tato, a audição e mesmo, em alguns casos, o olfato. Ela é constituída por "um conjunto de 
representações artificiais que trabalham com uma concepção limitada de percepção" (SIQUEIRA, 2006: 61) A idéia de percepção limitada contraria, de certa forma, a noção de Merleau-Ponty de que o mundo é conhecido e nos conhece através do corpo. Se os dados perceptuais que recebemos em dado momento nos causam uma sensação de realidade, mesmo que efêmera, podemos dizer que essa é uma realidade válida que se nos apresenta à consciência, para falar fenomenologicamente.

A idéia do que seria "artificial" e do que seria "natural" não se sustentam quando encaramos o contato com a realidade empírica segundo um modelo husserliano: não é possível o contato direto com o mundo natural. Também não podemos, como quer o idealismo transcendental de Husserl, ignorar o papel fundamental do corpo na apreensão do mundo. A idéia de "esquema corporal", sugerida por Merleau-Ponty, nos oferece boas ferramentas para encararmos o corpo como um a priori nessa relação com as coisas.

Talvez possamos pensar como outras formas de imersão, bem mais antigas, também trabalhavam para diminuir as distâncias entre os universos vividos e representados. Os panoramas do século XIX utilizavam uma pintura realista e de grandes proporções para envolver completamente o espectador. A música, aromas e mesmo objetos tridimensionais, os faux terrain, contribuíam para um trompe les sens. Naturalmente essa ilusão durava algum tempo e era logo em seguida substituída pela distância crítica da platéia. Não seriam também esses recursos métodos artificiais de se estimular os sentidos? E quando a tecnologia permitir uma ilusão sem fim? Um processo onde não poderíamos vislumbrar os limites entre real e simulado? Poderíamos ainda falar de real e simulado? Talvez mesmo assim o mundo (seja ele qual for) possa ainda se apresentar aos sentidos humanos (sejam eles quais forem).

O que é colocado em questão aqui não é a mera aptidão do corpo para esta ou aquela tarefa, mas de que corpo estamos falando. Quais são seus limites? Até onde nossa pele, já tendo experimentado sensações expandidas, mediadas pelos aparelhos sensórios, é o limite desse corpo? Até onde o corpo orgânico ainda é a parte mais representativa do que é ser humano? Podemos falar de forma tão generalizante de idéias tão diferentes de "corpo"?

Claro que essas questões estão longe de se resolverem. Elas não são sequer recentes. O corpo dividido, a dualidade matéria/espírito ou corpo/alma, como articulada por Descartes, tem sido objeto de críticas e reapropriações.

Para Descartes, a mente é a prova final de nossa existência. A mente foi objeto de escolha de Descartes por atender à demanda da razão iluminista. Muito embora não explicasse muito bem como se dava o relacionamento entre a mente (res cogitans) e o corpo (res extensae) era à mente que o filósofo atribuía o caráter de imprescindível. Ela poderia ainda ser pensada mesmo que o corpo não existisse, era o fundamento do "eu”. A mente é precisa. "Eu não sou essa reunião de membros que se chama o corpo humano" (DESCARTES, 1988: 26). 
Esse tipo de pensamento vai ser retomado hoje em dia por um discurso neocartesiano que considera a mente passível de redução a padrões binários. Pensadores como o artista plástico Stelarc encaram o corpo como algo obsoleto e aquém das necessidades humanas. Ele é frágil, antiquado, ineficiente.

As tecnologias estão se tornando melhores sistemas de apoio à vida para nossas imagens do que para nossos corpos. Magens são imortais, corpos são efêmeros. O corpo acha cada vez mais difícil corresponder às expectativas de suas imagens. No domínio das imagens morfing e da multiplicação, a impotência do corpo físico é aparente (STELARC, 1997: 62).

As tecnologias seriam mais do que a cristalização dos processos culturais humanos, elas se tornariam o próprio homem.

\section{We are the Robots}

$\mathrm{Na}$ idade moderna, alvo de um projeto disciplinador, o corpo passa a ser esquadrinhado, considerado cartesianamente. O médico Julien Offray de La Mettrie, na primeira metade do século XVIII, passa a encará-lo como máquina. La Mettrie descartou a alma como objeto de estudo, uma vez que não podia ser constatada fisicamente (SIBILIA, 2002).

Para Katherine Hayles, em um primeiro momento da cibernética, entre 1943 e 1954, pesquisadores como Norbert Wiener estabeleceram um novo paradigma científico onde o funcionamento do cérebro humano era comparado ao de computadores (HAYLES, 1999). O importante nessa concepção é que a informação, traduzida em um código binário, perdia sua referência com qualquer corpo. Tratam-se agora de padrões que podem ser transmitidos de um meio ao outro, independentemente de um peso, de uma massa corpórea. Fica implícito que as diferenças entre homens e máquinas cerebrais são pequenas (se é que as há). Os homens são "entidades que processam informações e que são essencialmente similares às máquinas inteligentes" (HAYLES, 1999: 7).

Hayles expõe a dualidade entre materialidade e informação. A informação é essencialmente imaterial e funciona por padrões. Só assim pode ser manipulada e transmitida com facilidade. O caráter aleatório da matéria a manteria prisioneira de uma imperfeição, uma não funcionalidade.

Dessa forma, ao perder seu peso, a informação coloca em xeque o peso do próprio corpo. É claro que isso pode ser levado a extremos como em concepções que defendem que o corpo não é mais adequado à nossa vida. A barroquização (MAFFESOLI, 1996), o excesso de imagens da pós-modernidade, não pode ser contido por um corpo orgânico. "O córtex anseia por informação, mas não consegue mais contê-la e processá-la criativamente. Como pode um corpo compreender subjetiva e simultaneamente nanossegundos e nebulosas?" (STELARC, 1997: 53). 
Pensar o corpo como máquina significa esperar daquele o que seria essencial nesta. Desempenho, eficiência. Essa eficiência é proclamada durante o show do Kraftwerk em vários momentos. Seja ao falar de materiais de alta resistência (Titanium), de substâncias químicas para melhorias físicas e mentais (Vitamin) ou de modelos de performance (Aéro Dynamik). É o que se espera do corpo em um mundo de máquinas. Mesmo que para isso precisemos mudar o que temos de mais humano, mais natural. Pois foi isso que aconteceu quando percebeu-se que o código genético poderia ser reduzido a um padrão binário. O que antes era considerado aleatório, era agora padronizado.

O código genético revelou-se a chave para a perfeição. Doenças poderiam ser curadas. Deficiências removidas. A possibilidade de uma eugenia ameaçou a ciência do século XX. Com o estabelecimento do Projeto Genoma Humano, em 1990, não apenas a idéia de um homem criador à maneira de Deus, mas também a idéia de uma perfeição alcançável passou a povoar o imaginário científico.

O desenvolvimento da engenharia genética humana, como nos diz André Lemos, tem como uma de suas fontes de inspiração o conjunto de mitos onde a vida humana é criada artificialmente (LEMOS, 2004). O Golem, o elixir da vida ou o Frankenstein de Mary Shelley.

O corpo é passível de remodelagens. Drogas, próteses tecnológicas, terapia genética, são apenas algumas das maneiras de tornar esse corpo apropriado aos dias de hoje. O uso de tais dispositivos tecnológicos, criando um híbrido de homem e máquina vai suscitar uma condição pós-humana. O processo de virtualização e de configuração de uma rede onde a informação não segue o esquema unidirecional dos meios analógicos, e sim um modelo todos-para-todos, vai gerar a idéia do cibercorpo.

O que causa o surgimento do gênero humano, e sua supremacia sobre os demais animais, é justamente a possibilidade, em construindo a cultura, de elevar-se acima da natureza e para além dela. O processo de cyborgização contemporâneo nada mais é que a continuação inelutável dessa ordem à parte formada pelo homem, de sua saída da natureza na construção de uma segunda ordem artificial (LEMOS, 2004: 165).

Os ciborgues são caracterizados por seu organismo híbrido. André Lemos distingue os ciborgues protéticos dos ciborgues interpretativos. Os primeiros simbolizam a simbiose entre o orgânico e o inorgânico.

O cyborg interpretativo se constitui pela influência dos mass media, coagido que é pelo poder da televisão ou do cinema. Assim, a cultura de massa e do espetáculo nos fez cyborgs interpretativos (LEMOS, 2004: 172).

Donna Haraway vê os ciborgues como donos de uma sexualidade híbrida. Possuem uma identidade parcial e contraditória, "uma criatura de realidade social e também uma criatura de ficção" (HARAWAY, 2000: 40) O ciborgue é fruto de três fatores. O primeiro seria a ruptura entre a natureza e a cultura. O segundo é a contradição entre homem e máquina, que ele assumiria ao fomentar o convívio de suas partes orgânicas e 
inorgânicas. O terceiro fator é a separação entre o físico e o não-físico. A desmaterialização numérica do mundo leva todos os processos sociais a serem pensados a partir da virtualização. O ciborgue nasce desse processo de numerização.

Ainda sobre essa cisão entre material e imaterial, entre natural e não natural, David Noble cita a obra do cientista britânico J. D. Bernal: Uma pesquisa sobre o futuro dos três inimigos da alma racional. Nessa obra de 1969, Bernal aponta como inimigos dessa alma racional a natureza, o corpo e os desejos e emoções humanos. Para escapar do primeiro o autor propõe a construção de ambientes artificiais na órbita terrestre. Biosferas distantes da ruína natural. Para combater o segundo inimigo ele propõe retirar o cérebro do corpo e mantê-lo funcionando por meio de máquinas. Afinal, o que conta é a mente. Finalmente, apesar de ver como obstáculo mais difícil, Bernal sugere uma disciplina monástica para combater os desejos humanos. Desse modo, a elite descorporificada poderia substituir um ambiente apático por um planejado e criado exclusivamente por ela.

Todo cuidado é pouco ao analisarem-se todos os processos humanos a partir dos padrões binários da informação. Adroaldo Gaya chama esse reducionismo de princípio do "cérebro num barril" (GAYA, 2006: 263). Dizer que apenas a lógica da razão formal e seus processos de descorporificação da informação podem ser produtores de conhecimento é uma posição limitada e não abrange o todo do universo humano.

É importante recordar que sobrevivemos neste planeta como animais, mesmo antes de desenvolver a consciência. E sobrevivemos porque aprendemos. Desenvolvemos estratégias, criamos conhecimentos que nos permitiram permanecer na face da terra. Ou será que nossas emoções, nossos sentimentos não são eles próprios formas evidentes de conhecimentos? Os sentidos que nos permitem perceber os sons, os perfumes, os ritmos, as consistências e as cores não estão intimamente envolvidos nas operações de nosso conhecimento racional? Adaptamo-nos às exigências e sobrevivemos. Desenvolvemos conhecimentos (GAYA, 2006: 264-265).

\section{Minimum maximum beats per minute}

A descorporificação não é um fenômeno restrito unicamente aos corpos humanos. Ela perpassa todas as relações contemporâneas e está presente em todas as esferas, da social à econômica. Jeremy Rifkin nos mostra como o capitalismo vai se modificando a partir de princípios de desmaterialização dos objetos muito próximos aos da desmaterialização dos corpos (RIFKIN, 2001). A propriedade das coisas, exemplo bastante forte dessa relação com a matéria, está deixando de ser uma condição necessária à satisfação de desejos em nossa sociedade. O objeto em si está sendo, aos poucos, substituído pela experiência, pelo acesso. Em um momento em que a velocidade é fator decisivo para qualquer experiência, todo tipo de obstáculo ao livre fluir dos eventos torna-se indesejável. É preciso tornar as experiências mais rápidas e efêmeras para que possamos consumir outras experiências. Nesse sentido os corpos são dispensados. A experiência, assim como a informação, necessita da redução binária para propagar-se. Percebe-se então o quanto a cultura, como 
produtora de experiências veiculadas pelos novos meios massivos e em rede, tornou-se a área chave do consumo pós-moderno.

O acúmulo do capital e de bens caracterizou a Era Industrial. Hoje, as formas de poder não possuem peso, são vinculadas a experiências, informações. Os produtos tangíveis vão perdendo sua condição de medida de riquezas. Os patrimônios de pessoas e empresas estão se desmaterializando. Há muito mais dinheiro em transações virtuais do que o que pode ser fisicamente movimentado com papel moeda. $\mathrm{O}$ dinheiro não tem mais seu peso em ouro, transformou-se em dados nos processos eletrônicos de bancos e governos.

Como ilustra Rifkin, o mercado, outrora ambiente físico, desloca-se para o universo das redes, das relações virtuais.

A mudança no comércio primário do espaço geográfico para o ciberespaço representa uma das maiores mudanças na organização humana e precisa ser entendida adequadamente, na medida em que traz consigo grandes mudanças na própria natureza da percepção humana e da comunicação social. Provavelmente em nenhum lugar, essas mudanças terão um impacto maior que em nossas noções de propriedade. Enquanto em uma economia baseada no espaço geográfico os vendedores e compradores trocam bens e serviços, no ciberespaço, servidores e clientes provavelmente trocarão informações, conhecimentos, experiências e mesmo fantasias. No âmbito anterior, a meta é a transferência de propriedade, enquanto no novo âmbito, a meta é fornecer acesso para a experiência diária de alguém (RIFKIN, 2001: 13).

Tanto Rifkin quanto Hayles apontam para essa desmaterialização do mundo físico, muito embora admitam que num mundo de trocas de informações cada vez mais rápidas, mais da metade da população da Terra nem sequer tem a possibilidade de fazer um telefonema. A valorização das experiências em detrimento do corpo físico, o intangível em vez do tangível é, notadamente, um tipo de pensamento que floresce em uma sociedade cada vez mais dependente das tecnologias. Mas talvez não devêssemos pensar que a proliferação das máquinas, sua invenção e sua substituição por outras máquinas mais modernas, seja condição sine qua non para a manutenção desse tipo de pensamento. Talvez o contrário seja mais correto. Quanto mais rápido trocamos uma tecnologia por outra mais evidente fica o quanto as máquinas sensórias e cerebrais estão deixando de ser prolongamentos do homem para, aos poucos, tornarem-se o próprio homem. No fundo, a troca, a evolução de tecnologias, poderia ser encarada, de uma maneira radical, como uma evolução da espécie.

A comunicação em rede, com seus infinitos pontos e a diluição inerente a essa estrutura rizomática, aponta para a conformação de um tipo de pensamento que não se prende muito tempo em um lugar. Esse nomadismo vai construindo um imaginário que não é verdadeiro para o mundo em geral. Aliás, não é possível para a grande maioria. A tecnologia é, também, fator de exclusão. A experiência, o acesso, o Sol da virtualização não brilha para todos. Aos que, na maior parte do globo, não conseguem usufruir dos benefícios desse admirável mundo novo, resta a âncora do mundo físico. 
A disciplina, detectada por Foucault, cede espaço para uma sociedade do controle, onde as relações são muito menos explícitas. A liberdade é constantemente colocada em xeque por mecanismos cada vez mais inteligentes. Não há como se esconder ou fugir do esquadrinhamento tecnológico. O panóptico tornou-se muito mais amplo e eficiente.

\section{Planet of visions}

O curioso em relação à técnica atualmente é, justamente, sua simbiose inusitada com a socialidade. Novas tribos surgem. Compartilham ideais e imaginários. Apesar da racionalidade técnica, o ser humano procura novas formas de organização em grupo. Talvez estejamos buscando através das tecnologias uma nova forma de agregação social. Um caráter planetário de uma nova socialidade

David Noble também nos mostra o quanto o pensamento científico não consegue desprender-se de uma transcendência, uma gnose. Ele cita Robert L. Sinsheimer, pesquisador norte-americano que defendia, nos anos 80, um esforço coordenado para "mapear" e "seqüenciar" todo o genoma humano com financiamento do governo. "Pela primeira vez em todos os tempos uma criatura viva compreende sua origem e pode tentar projetar o seu futuro.” (apud NOBLE, 1999: 189). Sinsheimer completa:

Talvez esse anseio seja uma réplica ao destino, uma recusa à mortalidade humana. Eu sou um cientista, um membro de uma das mais afortunadas espécies. As vidas da maioria das pessoas são repletas do efêmero... Mas uns poucos felizardos de nós têm o privilégio de conviver com e explorar o eterno (apud NOBLE, 1999: 189).

Precisamos, contudo, ficar atentos para o fato de que essa utopia planetária, essa inteligência coletiva, como denomina Pierre Lévy, está muito longe de ser alcançada. Ainda não dispomos de acesso às experiências de uma maneira abrangente. A questão aqui não é analisar o quanto a virtualização dos corpos nos aproxima de uma eternidade mística ou de um projeto fáustico de recriação de um homem ampliado. Foucault nos fala dessa utopia do corpo:

Meu corpo: ele é o lugar sem escape ao qual eu estou condenado. Verdadeiramente eu penso que é contra esse corpo (como se para apagá-lo) que todas as utopias surgiram. O prestígio da utopia - a que a utopia deve sua beleza, seu caráter prodigioso? A utopia é um lugar fora de todos os lugares, mas é um lugar onde eu terei um corpo sem um corpo, um corpo que será bonito, límpido, transparente, luminoso, veloz, colossal em seu poder, infinito em sua duração. Sem limites, invisível, protegido - sempre transfigurado. Bem pode ser que a primeira utopia, aquela mais profundamente arraigada nos corações dos homens seja precisamente a utopia de um corpo incorpóreo (FOUCAULT, 2006: 229).

Não se trata de condenar, nem de defender. O importante é perceber o quanto esse imaginário entranhase na sociedade e o quanto ele alija os que não podem participar desse projeto, ficando com as sobras, como 
sempre aconteceu na história da humanidade. Nesse sentido, a virtualização do mundo não é nada assim tão diferente do que sempre tem sido.

\section{Conclusões}

O show do Kraftwerk, e algumas das idéias que ali se apresentam, é apenas uma ponta em um imenso iceberg de reapropriações dessa dualidade cartesiana entre mente e corpo. Essa valorização de um elemento em detrimento do outro perpassa uma série de representações mais profundas e emerge como se fosse algo recente na história da humanidade. Não é bem assim. Talvez o que diferencie essa necessidade de se ver o corpo como algo menor, imperfeito, seja o caráter estético que ela assumiu. O excesso de imagens, essa "barroquização", como diz Maffesoli, é capaz afetar mais intensamente nossa relação com o mundo material, tanto que, mesmo fora do âmbito estético, o mundo já envereda por caminhos que questionam a nossa relação com a própria realidade física. Mas esta ainda resiste.

O corpo humano, como tudo o que é sólido, também desmancha no ar.

\section{NOTAS}

Trabalho apresentado no III Congresso de Estudantes de Pós-Graduação em Comunicação - CONECO 3, na Universidade do Estado do Rio de Janeiro, 2008.

(1) Composições da banda, apresentadas no show. Também são usados trechos de músicas como títulos das seções deste texto.

(2) Representação eletrônica usada para modelagem virtual de corpos tridimensionais. Os vértices e linhas do objeto são representados de maneira simples, entrelaçados, na forma de aramado.

(3) Movimento musical do final dos anos 40 e dos anos 50, do qual Pierre Schaeffer foi um dos pioneiros. Utilizava em suas composições sons gravados e não necessariamente musicais ou produzidos por instrumentos tradicionais.

(4) Movimento musical, inaugurado por Herbert Eimert - com seus experimentos na Rádio alemã NWDR, em Colônia que privilegia o uso de instrumentos musicais ou aparelhos de natureza eletrônica em suas composições. Teve um período de crescimento na década de 50, por conta dos avanços tecnológicos na área. Algumas experiências, como a invenção do Theremin (1919), datam do final do século XIX e início do século XX.

\section{Referências}

DELEUZE, Gilles. Conversações. Rio de Janeiro: Editora 34, 1992.

DESCARTES, René. “Meditações.” In: Descartes (Coleção "Os Pensadores").São Paulo: Nova Cultural, 1988. FOUCAULT, Michel. "Utopian body." In: JONES, Caroline A. (ed.). Sensorium: embodied experience, technology, and contemporary art. Massachussets: The MIT Press, 2006. 
. Vigiar e punir. Petrópolis: Vozes, 2007.

GAYA, Adroaldo. “A reinvenção dos corpos: por uma pedagogia da complexidade”. In: Sociologias, jan.-jun, 2006.

HARAWAY, Donna. "Manifesto ciborgue: ciência, tecnologia e feminismo-socialista no final do século XX". In: SILVA, Tomaz Tadeu da (org.). Antropologia do ciborgue. Belo Horizonte: Autêntica, 2000.

HAYLES, N. Katherine. How we became posthuman: virtual bodies in cybernetics, literature, and informatics. Chicago: The University of Chicago Press, 1999.

LEMOS, André. Cibercultura: tecnologia e vida social na cultura contemporânea. Porto Alegre: Sulina, 2004. LÉVY, Pierre. Cibercultura. São Paulo: Editora 34, 1999.

. O que é o virtual? São Paulo: Editora 34, 1996.

MAFFESOLI, Michel. No fundo das aparências. Petrópolis: Vozes, 1996.

McLUHAN, Marshall. Os meios de comunicação como extensões do homem. São Paulo: Cultrix, 2005.

MERLEAU-PONTY, Maurice. O primado da percepção e suas conseqüências filosóficas. Campinas: Papirus, 1990.

NOBLE, David, F. The religion of technology: the divinity of man and the spirit of invention. London: Penguin Books, 1999.

RIFKIN, Jeremy. A era do acesso: a transição de mercados convencionais para networks e o nascimento de uma nova economia. São Paulo: Makron Books, 2001.

RUSSOLO, Luigi. L'arte dei rumori. Milano: Tip. Taveccia, 1916.

SANTAELLA, Lucia. “O homem e as máquinas”. In: DOMINGUES, Diana (org.). A arte no século XXI: a humanização das tecnologias. São Paulo: Unesp, 1997.

SCHAEFFER, Pierre. Traité des objets musicaux. Paris: Seuil, 1966.

SCHAFER, R. Murray. A afinação do mundo. São Paulo: Unesp, 1997

SIBILIA, Paula. O homem pós-orgânico: corpo, subjetividade e tecnologias digitais. Rio de Janeiro: Relume Dumará, 2002.

SIQUEIRA, Denise da Costa Oliveira. Corpo, comunicação e cultura: a dança contemporânea em cena. Campinas: Autores Associados, 2006.

STELARC. "Das estratégias psicológicas às ciberestratégias: a protética, a robótica e a existência remota." In: DOMINGUES, Diana (org.). A arte no século XXI: a humanização das tecnologias. São Paulo: Unesp, 1997. VIRILIO, Paul. O espaço crítico. Rio de Janeiro: Editora 34, 1993. 